\title{
Influence of Discomfort Tolerance of Women who Undergo Mammography on the Perceived Pain Intensity Due to the Procedure
}

\author{
(D) Neriman Akansel ${ }^{1}$, (D) Muaz Gülşen², (1) Muhammed Gültaşş \\ ${ }^{1}$ Department of Surgical Nursing, Bursa Uludağ University, Nilüfer, Bursa, Turkey \\ ${ }^{2}$ Department of Surgical Nursing, Çukurova University Faculty of Health Sciences, Adana, Turkey
}

\begin{abstract}
Objective: This study aims to determine the capacity to tolerate discomfort by women who undergo mammography.

Materials and Methods: The data were obtained using the face-to-face interview method immediately after the procedure with women who undergo mammography $(\mathrm{n}=132)$. Demographic data collection form and the Discomfort Intolerance Scale was used for data collection.

Results: Among the women, $78.8 \%$ experienced pain during mammography and the pain intensity was determined as 3.55 (standard deviation=3.00) on the 0-10 Visual Analogue Scale. Women who were not on pain relievers and nonsmokers have high discomfort tolerance. Women who were consuming substances containing methylxanthine (eg. chocolate) tend to avoid discomfort. Women with a history of breast mass and abnormal test results did not avoid discomfort as much as women who undergo regular checkup mammograms. Most of the women experience pain during mammography, and avoidance from discomfort increases as the perceived pain during the procedure increases.

Conclusion: Conducting different studies using the same scale can be useful in evaluating the discomfort experienced during mammography and its contribution to reducing pain.
\end{abstract}

Keywords: Pain, Discomfort Intolerance Scale, mammography

Cite this article as: Akansel N, Gülşen M, Gültaş M. Influence of Discomfort Tolerance of Women who Undergo Mammography on the Perceived Pain Intensity Due to the Procedure. Eur J Breast Health 2021; 17(1): 68-75

\section{Introduction}

Cancer is the most frightening disease that causes mortality worldwide $(1,2)$. The most effective way to decrease the mortality rate is early diagnosis and treatment. American Cancer Society estimates 279,100 new breast cancer cases in 2020, and 42,690 of them are predicted to die due to breast cancer. Diagnosis of breast cancer includes a physical exam done by a physician as well as mammography $(3,4)$, and it is a reliable diagnosis method used all over the world (5-7). In mammography, breast radiography is obtained using a low dose of radioactive rays. With this procedure, early diagnosis and treatment are possible by detecting the structures that can turn into breast cancer years later (3). Recently, 3-dimensional (3D) mammography has become more popular in achieving better results. In medical imaging methods, the ability to detect pathological conditions depends on the image quality. Compression (pressure) is applied to the breast tissue in mammography to achieve this quality. This compression causes both pain and discomfort in the individuals $(5,8)$. Additionally, reasons such as the compressor material's being cold, claustrophobia in those who undergo mammography, lack of empathy of healthcare staff, not giving information about the procedure, prolongation of the reporting process cause patients to postpone having a mammography. Negative experiences encountered during mammography affect the patients' compliance, satisfaction, and comfort levels (9). Even the possibility of negative outcomes of mammography impress women's pain and satisfaction from mammography. Feeling of embarrassment and discomfort during the procedure could result in unpleasant perceptions toward this procedure (10). Whelehan et al. (11) reported that $3 \%-46 \%$ of British women did not comply with control mammography, due to previous pain and discomfort they experienced. Pain felt during a mammography is not only limited to the breast, it also could extend to the axilla as well (12). The women's ethnicity, breast density, previous biopsy experience, and psychological factors are causative factors of discomfort during mammography (9). Breast implants also trigger the pain and anxiety of women during the procedure (13).

A study published in the Cochrane database revealed that education is given to patients before mammography may decrease discomfort and pain felt during the procedure. Although using a breast pad decreases discomfort and paracetamol application is not effective (14). Freitas-Junior et al. (5) found that a capsule form of paracetamol given before the mammography procedure is effective in reducing moderate pain. Various studies have examined the effects of administering lidocaine (15), using Mammopad, Bedford, and mattresses (7, 10, 14, 16, 17), and reducing the 
compression force applied during mammography on reducing pain and discomfort due to mammography $(7,17,18-21)$. This study aims to assess the effect of the capacity to tolerate discomfort on the pain felt by women undergo mammography.

\section{Materials and Methods}

\section{Design}

This study was conducted with 132 women who had mammography at the Radiology Department of a University Hospital between February and April 2017 (for three months).

\section{Participants and settings}

A total of 225 patients were registered to have mammography for 3 months. Raousoft sample size calculator was used to calculate the sample size. With $90 \%$ reliability and 5\%, the error margin sample size was calculated as 124 patients.

\section{Measurements}

The data were obtained using the demographic data form developed by researchers according to relevant literature and the Discomfort Intolerance Scale (7 items) which was adapted to Turkish by Özdel et al. (22). The Discomfort Intolerance Scale (DIS) was originally developed by Schmidt et al. (23) to measure the personal differences to tolerate discomforting sensations. This scale has two dimensions named discomfort intolerance (DI-DI) and discomfort avoidance (DIDA). Split-half test reliability was 0.710 in the Turkish form of scale (DI-DI measures the capacity to tolerate physical sensations while DIDA measures the level of avoidance from physical sensations). Each item of the scale includes Likert type options numbered from 0 to 6 defined as; $0=$ not at all like me to $6=$ extremely like me $(22,23)$. The total score that can be obtained from the scale ranges from 0 to 42 . The lower scores describe a decline in the person's capacity to tolerate discomforting bodily sensations (22).

\section{Data collection procedure}

Data were collected by the researchers using face-to-face interview methods with patients who volunteered to participate in the study after mammography. Each interview took 10-15 minutes.

\section{Ethical consideration}

Ethical committee approval was obtained from the Bursa Uludag University (decision no: 2016-19/6) and institutional approval was obtained from the hospital where the study was going to be conducted The patients were informed that participation is voluntary, and they can leave the study whenever they want, then their verbal and written approvals were obtained.

\section{Data analysis}

Data analysis was done by SPSS. Normality analysis was done using the Shapiro-Wilk test. Data were presented in numbers, percentages, means, and SD. T-test, One-Way ANOVA, and Pearson correlation was used for statistical analysis.

\section{Results}

Table 1 shows the descriptive characteristics of patients who undergo mammography. The mean age of the patients was 55.62 [standard deviation $(\mathrm{SD})=9.83$ ] and their Body Mass Index (BMI) was calculated as $29.62(\mathrm{SD}=6.05)$. More than half of the participants $(52.2 \%)$ were primary school graduates. The rate of undergoing mammography
Table 1. Descriptive features of patients

Descriptive variables
Age (years)
Body Mass Index (BMI)
Bra size
Age of menopause (years)
Pain during mammography (VAS 0-10)

Mean \pm SD

$55.62 \pm 9.83$

$29.62 \pm 6.05$

$81.56 \pm 27.80$

$39.02 \pm 18.16$

$3.55 \pm 3.00$

n

$\%$

\section{Marital status}

Single

\section{Education level}

Elementary school graduate + able to read and write

Secondary school + high school

\section{Financial status}

Good

Fair

\section{Place of living}

City

Town + country

\section{Profession}

Salaried employee

Housewife

Retired

\section{Health coverage}

Available

\section{Health behaviors}

\section{Cigarette smoking}

Yes

No

Consuming chocolate

Yes

\section{Drinking tea}

Yes

\section{Drinking coffea}

Yes

Taking pain relievers whenever pain persists

Yes

\section{Breast $\mathrm{Ca}$ in immediate relatives}

\section{Yes}

No 
Table 1. Continued
Yes

No

110

83.3

Yes

No

Previous mammography experience

Yes

No

Pain during mammography

Yes

No

Feature of pain during mammography

Crushing + stinging

No answer

Frequency of having mammography

Every year

Every two years

Irregular

Never had mammography

Reason for having mammography now

Check up

Other (abnormal test results etc.)

Total

Reason for not having mammography ( $\left.n^{\beta}=22\right)$

Not having any symptoms

Other (fear, being young, not having any knowledge, etc.)

Total

22

\section{Being in menopause}

Breast sensitivity

BNumber of women never had mammography before VAS: Visual analogue scale; Ca: Cancer; SD: Standard deviation; n: Number

annually was $57.6 \%$, and $75.8 \%$ of women reported having control mammography (Table 1).

Table 2 shows the effect of patients' demographic characteristics on their DIS scores. As the BMI and weight increase, women tend to have more discomfort, and their score increase $(\mathrm{p}<0.05)$. Nonsmoking women had more discomfort tolerance power than smokers $(\mathrm{p}<0.05)$. The chocolate-eating routine had significantly increased DI-DA scores of women $(p<0.05)$, and women who custom to take analgesics for their pain regularly were more intolerant to discomfort $(\mathrm{p}<0.05)$. The patients' other demographic variables did not have any influence on their discomfort $(\mathrm{p}>0.05)$ (Table 2).

Table 3 shows the influence of women's mammography-related characteristics on their DIS scores. Characteristics of pain felt during mammography did not influence discomfort intolerance scale scores who reported crushing and stinging pain during mammography $(\mathrm{p}<0.01)$ (Table 3).

\section{Discussion and Conclusion}

Not having breast tenderness is associated with feeling less pain during mammography (24). The majority of the patients (75\%) who underwent mammography did not report any breast tenderness and most of them were not used to take pain relievers. This study did not assess whether the analgesics that the patients used were prescribed. The majority of the patients $(78.8 \%)$ reported having pain during mammography, and the pain intensity was calculated as $3.55(\mathrm{SD}=3.00)$ on Visual Analogue Scale 0-10 (VAS 0-10); $(0=$ no pain, $10=$ intense pain), the pain characteristics were mostly crushing/stinging (Table 1). The presence of a mass in the breast and abnormal findings on physical examination are associated with extreme pain during the mammography (24). Yilmaz and Kiymaz (25) emphasized that patients may experience anxiety due to the possibility of being diagnosed with cancer. The burden of having a mammography, feeling discomfort, and being anxious resulted in dissatisfaction with mammography (26). Sufficient knowledge of the procedure tend to decrease the anxiety among women (25), and pain perception is usually associated with personal sensitivity rather than the pressure itself (12). The presence of a breast mass and previous abnormal tests may have influenced the majority of the women's pain perception. Therefore, not starting the mammography procedure with the tender breast may decrease the unpleasant outcomes of the procedure (12). Pain and discomfort are subjective concepts that vary among people. While a study revealed that the explanatory information given to patients decreased pain sensation due to procedure (24), another study emphasizes that written information provided did not influence susceptibility to procedural pain (25). Additionally, applying standardized pressure results in less pain, less discomfort, and prevents excessive compression especially in smallbreasted women (8). Pain felt during mammography with flexible and standard compression did not differ between groups, and $34 \%$ of them experienced moderate or severe discomfort (20). A study conducted with experimental and control groups showed that the severity of pain during the mammography was 3.5 in the experimental group that took paracetamol, while it was 2.9 in the placebo group (5).

Some of the demographic characteristics (age, breast size, marital status, education, income level, place of residence, profession, breast cancer history in first degree relatives, being in menopause, presence of breast tenderness, tea-drinking routine) of the patients in this study did not have any influence on DIS and sub-dimension scores (Table 2). Another study found that age, education level, breast size, breast cancer history in first degree relatives, being in menopause, and drinking coffee did not influence the pain experience and discomfort due to mammography (5). Chan et al. (7) reported that the age and breast size of women were not related to the discomfort felt during mammography. They also found that Mamopad application significantly decreased the discomfort experienced during mammography, and women with low breast density experienced less discomfort. On the contrary, there is also a study showing that smaller breasts are more sensitive to the compression that occurs during mammography $(12,18)$. Thus mammography procedure applied with the pressure standardization method in women with small breast decreased the pain and discomfort felt during the procedure $(8,21)$. Moreover, it provided better results on the image quality, and eased the diagnosis process (8). A study conducted with technicians who take 
Table 2. Influence of patients' demographic variables on discomfort intolerance scale scores

\begin{tabular}{|c|c|c|c|c|c|c|}
\hline \multirow[b]{2}{*}{ Age } & & \multicolumn{2}{|c|}{$\begin{array}{l}\text { Discomfort Intolerance } \\
\text { Scale (DIS) }\end{array}$} & \multicolumn{2}{|c|}{$\begin{array}{l}\text { Discomfort Intolerance } \\
\text { (DI-DI) }\end{array}$} & \multirow{2}{*}{$\begin{array}{c}\begin{array}{c}\text { Discomfort } \\
\text { Avoidance } \\
\text { (DI-DA) }\end{array} \\
r=-0.027 \\
\mathrm{p}=0.761\end{array}$} \\
\hline & & $\begin{array}{l}r=0.020 \\
p=0.817\end{array}$ & - & $\begin{array}{l}r=0.105 \\
p=0.233\end{array}$ & - & \\
\hline Weight (kg) & & $\begin{array}{r}r=-0.193^{*} \\
p=0.027\end{array}$ & - & $\begin{array}{l}r=-0.151 \\
p=0.084\end{array}$ & - & $\begin{array}{l}r=-0.101 \\
p=0.250\end{array}$ \\
\hline Body Mass Index (BMI) & & $\begin{array}{c}r=-0.250 * * \\
p=0.004\end{array}$ & - & $\begin{array}{l}r=-0.210 * \\
p=0.016\end{array}$ & - & $\begin{array}{l}r=-0.093 \\
p=0.293\end{array}$ \\
\hline \multirow[t]{2}{*}{ Bra size } & & $\begin{array}{l}r=0.020 \\
p=0.821\end{array}$ & - & $\begin{array}{l}r=-0.037 \\
p=0.679\end{array}$ & - & $\begin{array}{l}r=0.044 \\
p=0.621\end{array}$ \\
\hline & n & Mean \pm SD & n & Mean \pm SD & $\mathbf{n}$ & Mean \pm SD \\
\hline \multicolumn{7}{|l|}{ Marital status } \\
\hline Single & 26 & $18.88 \pm 3.91$ & 26 & $12.92 \pm 4.53$ & 26 & $8.28 \pm 4.45$ \\
\hline Married & 106 & $\begin{array}{c}18.81 \pm 4.77 \\
t=0.072 \\
p=0.942\end{array}$ & 106 & $\begin{array}{c}13.42 \pm 4.50 \\
t=-0.499 \\
p=0.619\end{array}$ & 106 & $\begin{array}{c}6.77 \pm 4.13 \\
t=1.617 \\
p=0.108\end{array}$ \\
\hline \multicolumn{7}{|l|}{ Education level } \\
\hline Elementary school + able to read/write & 69 & $18.45 \pm 472$ & 69 & $13.43 \pm 4.24$ & 69 & $6.30 \pm 4.22$ \\
\hline Secondary school + high school & 37 & $18.86 \pm 4.84$ & 37 & $12.78 \pm 5.07$ & 37 & $7.78 \pm 4.17$ \\
\hline University graduate & 26 & $\begin{array}{c}18.83 \pm 4.60 \\
F=0.776 \\
p=0.462\end{array}$ & 26 & $\begin{array}{c}13.77 \pm 4.38 \\
F=0.413 \\
p=0.663\end{array}$ & 26 & $\begin{array}{c}8.08 \pm 4.00 \\
F=2.439 \\
p=0.091\end{array}$ \\
\hline \multicolumn{7}{|l|}{ Financial status } \\
\hline Good & 18 & $18.11 \pm 4.89$ & 18 & $12.05 \pm 4.59$ & 18 & $7.94 \pm 4.49$ \\
\hline Fair & 105 & $18.76 \pm 4.38$ & 105 & $13.34 \pm 4.39$ & 105 & $7.01 \pm 4.18$ \\
\hline Bad & 9 & $\begin{array}{c}22.57 \pm 6.21 \\
F=2.585 \\
p=0.079\end{array}$ & 9 & $\begin{array}{c}16.71 \pm 4.88 \\
F=2.763 \\
p=0.067\end{array}$ & 9 & $\begin{array}{c}6.28 \pm 4.46 \\
F=0.504 \\
p=0.606\end{array}$ \\
\hline \multicolumn{7}{|l|}{ Place of living } \\
\hline City & 121 & $18.74 \pm 4.55$ & 121 & $13.12 \pm 4.39$ & 121 & $7.24 \pm 4.25$ \\
\hline Town + country & 11 & $\begin{array}{c}19.73 \pm 5.27 \\
t=-0.067 \\
p=0.500\end{array}$ & 11 & $\begin{array}{c}15.54 \pm 5.20 \\
t=1.731 \\
p=0.086\end{array}$ & 11 & $\begin{array}{c}5.09 \pm 3.33 \\
t=1.630 \\
p=0.106\end{array}$ \\
\hline \multicolumn{7}{|l|}{ Profession } \\
\hline Salaried employee & 7 & $16.71 \pm 6.78$ & 7 & $11.43 \pm 5.59$ & 7 & $6.71 \pm 5.65$ \\
\hline Housewife & 43 & $19.14 \pm 3.89$ & 43 & $13.42 \pm 4.06$ & 43 & $7.74 \pm 4.35$ \\
\hline Retired & 82 & $\begin{array}{c}18.84 \pm 4.75 \\
F=0.835 \\
p=0.436\end{array}$ & 82 & $\begin{array}{c}13.43 \pm 4.63 \\
F=0.651 \\
p=0.660\end{array}$ & 82 & $\begin{array}{c}6.73 \pm 4.02 \\
F=0.839 \\
p=0.435\end{array}$ \\
\hline \multicolumn{7}{|l|}{ Smoking } \\
\hline Yes & 19 & $16.68 \pm 5.45$ & 19 & $10.84 \pm 4.68$ & 19 & $7.17 \pm 4.83$ \\
\hline No & 113 & $\begin{array}{c}19.19 \pm 4.37 \\
t=-2.225 \\
p=0.028\end{array}$ & 113 & $\begin{array}{c}13.73 \pm 4.35 \\
t=2.657 \\
p=0.009\end{array}$ & 113 & $\begin{array}{c}7.04 \pm 4.13 \\
t=0.114 \\
p=0.909\end{array}$ \\
\hline \multicolumn{7}{|l|}{ Consuming chocolate } \\
\hline Yes & 30 & $18.33 \pm 4.77$ & 30 & $11.90 \pm 4.58$ & 30 & $8.48 \pm 3.97$ \\
\hline No & 101 & $\begin{array}{c}18.93 \pm 4.57 \\
t=-0.622 \\
p=0.535\end{array}$ & 101 & $\begin{array}{c}13.70 \pm 4.41 \\
t=1.949 \\
p=0.053\end{array}$ & 101 & $\begin{array}{l}6.62 \pm 4.22 \\
t=-2.117 \\
p=0.036\end{array}$ \\
\hline
\end{tabular}


Table 2. Continued

\begin{tabular}{|c|c|c|c|c|c|c|}
\hline & \multicolumn{3}{|c|}{$\begin{array}{l}\text { Discomfort Intolerance } \\
\text { Scale (DIS) }\end{array}$} & \multicolumn{2}{|c|}{$\begin{array}{l}\text { Discomfort Intolerance } \\
\text { (DI-DI) }\end{array}$} & \multirow{2}{*}{$\begin{array}{c}\text { Discomfort } \\
\text { Avoidance } \\
\text { (DI-DA) } \\
\text { Mean } \pm \text { SD }\end{array}$} \\
\hline & n & Mean \pm SD & $\mathbf{n}$ & Mean \pm SD & $\mathbf{n}$ & \\
\hline \multicolumn{7}{|c|}{ Drinking tea } \\
\hline Yes & 124 & $18.83 \pm 4.58$ & 124 & $13.33 \pm 4.30$ & 123 & $7.05 \pm 4.19$ \\
\hline No & 8 & $\begin{array}{c}18.75 \pm 5.20 \\
t=-0.48 \\
p=0.962\end{array}$ & 8 & $\begin{array}{c}13.13 \pm 7.22 \\
t=0.125 \\
p=0.901\end{array}$ & 8 & $\begin{array}{l}7.25 \pm 4.89 \\
t=-0.130 \\
p=0.896\end{array}$ \\
\hline \multicolumn{7}{|c|}{ Drinking coffee } \\
\hline Yes & 66 & $18.59 \pm 4.54$ & 66 & $12.95 \pm 4.18$ & 66 & $7.19 \pm 4.26$ \\
\hline No & 66 & $\begin{array}{c}19.06 \pm 4.69 \\
t=-0.585 \\
p=0.560\end{array}$ & 66 & $\begin{array}{l}13.68 \pm 4.79 \\
t=-0.930 p=0.354\end{array}$ & 66 & $\begin{array}{c}6.94 \pm 4.20 \\
t=0.332 \\
p=0.741\end{array}$ \\
\hline \multicolumn{7}{|c|}{ Breast Ca in immediate relatives } \\
\hline Yes & 24 & $17.48 \pm 3.96$ & 24 & $12.00 \pm 4.08$ & 24 & $7.00 \pm 4.40$ \\
\hline No & 108 & $\begin{array}{c}19.13 \pm 4.71 \\
t=1.576 \\
p=0.117\end{array}$ & 108 & $\begin{array}{c}13.65 \pm 4.53 \\
t=1.610 \\
p=0.110\end{array}$ & 108 & $\begin{array}{c}7.04 \pm 4.20 \\
t=-0.038 \\
p=0.969\end{array}$ \\
\hline \multicolumn{7}{|c|}{ Being in menopause } \\
\hline Yes & 110 & $18.96 \pm 4.31$ & - & $13.54 \pm 4.46$ & - & $7.02 \pm 4.17$ \\
\hline \multirow[t]{2}{*}{ No } & 22 & $18.14 \pm 5.92$ & & $12.23 \pm 4.60$ & & $7.27 \pm 4.55$ \\
\hline & - & $\begin{array}{l}t=0.623 \\
p=0.539\end{array}$ & - & $\begin{array}{l}t=1.251 \\
p=0.230\end{array}$ & - & $\begin{array}{l}t=-0.257 \\
p=0.797\end{array}$ \\
\hline \multicolumn{7}{|c|}{ Using pain relievers } \\
\hline Yes & 20 & $17.20 \pm 4.80$ & 20 & $11.05 \pm 4.78$ & 20 & $7.85 \pm 3.83$ \\
\hline No & 112 & $\begin{array}{c}19.12 \pm 4.53 \\
t=-1.728 \\
p=0.086\end{array}$ & 112 & $\begin{array}{c}13.72 \pm 4.34 \\
t=2.500 \\
p=0.014\end{array}$ & 112 & $\begin{array}{c}6.92 \pm 4.28 \\
t=0.909 \\
p=0.365\end{array}$ \\
\hline \multicolumn{7}{|c|}{ Breast sensitivity } \\
\hline Yes & 33 & $19.42 \pm 4.17$ & 33 & $13.42 \pm 3.72$ & 33 & $7.67 \pm 4.22$ \\
\hline No & 99 & $\begin{array}{c}18.63 \pm 4.74 \\
t=0.862 \\
p=0.390\end{array}$ & 99 & $\begin{array}{c}13.29 \pm 4.74 \\
t=0.156 \\
p=0.876\end{array}$ & 99 & $\begin{array}{c}6.86 \pm 4.22 \\
t=0.954 \\
p=0.342\end{array}$ \\
\hline
\end{tabular}

Tablo 3. Influence of patients' experiences related to mammography on Their Discomfort Intolerance Scale scores

\begin{tabular}{|c|c|c|c|c|c|c|}
\hline & \multicolumn{2}{|c|}{$\begin{array}{c}\text { Discomfort Intolerance } \\
\text { Scale (DIS) }\end{array}$} & \multicolumn{2}{|c|}{$\begin{array}{c}\text { Discomfort Intolerance } \\
\text { (DI-DI) }\end{array}$} & \multicolumn{2}{|c|}{$\begin{array}{c}\text { Discomfort Avoidance } \\
\text { (DI-DA) }\end{array}$} \\
\hline & $\mathbf{n}$ & Mean \pm SD & $\mathbf{n}$ & Mean \pm SD & $\mathbf{n}$ & Mean \pm SD \\
\hline \multicolumn{7}{|c|}{ Previous mammography experience } \\
\hline Yes & 110 & $19.06 \pm 4.55$ & 110 & $13.35 \pm 4.35$ & 110 & $7.38 \pm 4.31$ \\
\hline No & 22 & $\begin{array}{c}17.64 \pm 4.80 \\
t=1.332 \\
D=0.185\end{array}$ & 22 & $\begin{array}{c}13.18 \pm 5.27 \\
t=0.155 \\
D=0.877\end{array}$ & 22 & $\begin{array}{c}5.38 \pm 3.26 \\
t=2.017 \\
D=0.020\end{array}$ \\
\hline
\end{tabular}


Tablo 3. Continued

\begin{tabular}{|c|c|c|c|c|c|c|}
\hline & \multicolumn{2}{|c|}{$\begin{array}{l}\text { Discomfort Intolerance } \\
\text { Scale (DIS) }\end{array}$} & \multicolumn{2}{|c|}{$\begin{array}{l}\text { Discomfort Intolerance } \\
\text { (DI-DI) }\end{array}$} & \multicolumn{2}{|c|}{$\begin{array}{l}\text { Discomfort Avoidance } \\
\text { (DI-DA) }\end{array}$} \\
\hline & $\mathbf{n}$ & Mean \pm SD & $\mathbf{n}$ & Mean \pm SD & $\mathbf{n}$ & Mean \pm SD \\
\hline \multicolumn{7}{|c|}{ Pain severity during mammography (VAS $=0-10$ ) } \\
\hline & & $r=0.159$ & & $r=-0.110$ & & $r=0.361 * *$ \\
\hline & & $p=0.069$ & & $p=0.209$ & & $p=0.000$ \\
\hline \multicolumn{7}{|c|}{ Feature of pain experienced during mammography } \\
\hline No answer & 28 & $18.00 \pm 4.51$ & 28 & $14.07 \pm 4.21$ & 28 & $5.11 \pm 3.95$ \\
\hline \multirow[t]{3}{*}{ Crushing + stinging } & 104 & $19.05 \pm 4.62$ & 104 & $13.11 \pm 4.51$ & 104 & $7.56 \pm 4.15$ \\
\hline & & $t=-1.070$ & & $t=1.000$ & & $t=-2.841$ \\
\hline & & $p=0.287$ & & $p=0.322$ & & $p=0.005$ \\
\hline \multicolumn{7}{|l|}{ Frequency of having mammography } \\
\hline Every year & 76 & $19.07 \pm 5.58$ & 76 & $13.34 \pm 4.49$ & 76 & $7.46 \pm 4.42$ \\
\hline Every two years & 6 & $19.66 \pm 5.27$ & 6 & $13.33 \pm 5.53$ & 6 & $6.00 \pm 4.24$ \\
\hline Irregular & 28 & $18.89 \pm 4.45$ & 28 & $13.14 \pm 3.76$ & 28 & $7.46 \pm 4.10$ \\
\hline \multirow[t]{3}{*}{ Never had mammography } & 22 & $17.63 \pm 4.79$ & 22 & $13.18 \pm 5.27$ & 22 & $5.38 \pm 3.26$ \\
\hline & & $F=0.630$ & & $F=0.121$ & & $F=1.572$ \\
\hline & & $p=0.597$ & & $p=0.947$ & & $p=0.199$ \\
\hline \multicolumn{7}{|l|}{ Reason for having mammography now } \\
\hline Routine procedure & 108 & $19.13 \pm 4.59$ & 108 & $13.51 \pm 4.44$ & 108 & $7.36 \pm 4.41$ \\
\hline \multirow[t]{3}{*}{ Other (abnormal test results etc.) } & 24 & $17.46 \pm 4.48$ & 24 & $12.42 \pm 4.72$ & 24 & $5.62 \pm 2.81$ \\
\hline & & $t=-1.619$ & & $t=-1.088$ & & $t=-2.364$ \\
\hline & & $p=0.108$ & & $p=0.279$ & & $p=0.022$ \\
\hline \multicolumn{7}{|c|}{ Reason for not having mammography previously $\left(n^{\beta}=22\right)$} \\
\hline Not having any symptoms & 14 & $18.14 \pm 5.26$ & 14 & $13.43 \pm 5.75$ & 14 & $5.38 \pm 3.28$ \\
\hline \multirow{3}{*}{$\begin{array}{l}\text { Other (fear, being young, not having any } \\
\text { knowledge, etc.) }\end{array}$} & 8 & $16.75 \pm 4.03$ & 8 & $12.75 \pm 4.65$ & 8 & $5.39 \pm 3.46$ \\
\hline & & $t=0.646$ & & $t=0.284$ & & $t=0.006$ \\
\hline & & $p=0.526$ & & $p=0.779$ & & $p=0.995$ \\
\hline
\end{tabular}

mammography revealed that small breast size increased discomfort during mammography and the discomfort levels of women with high breast density during mammography were similar to that of women who had a previous lumpectomy or biopsy experience (9).

In this study patients' power to tolerate discomfort decreased as their weight increased. Similarly, the negative correlation between BMI and DIS score was evaluated that as the BMI increases, the patients' tolerance towards the disturbing stimulus decreases. Apart from the results of this study, Moshina et al. (27) found that BMI did not interfere with pain experienced due to compression paddle during mammography.

Women who did not use to taking pain relievers had significantly high DI. Not being able to tolerate discomfort is among the important risk factors on the emergence, development, and continuity of anxiety (28). In some studies, smoking is presented as an excuse to cope with stress, and individuals continue smoking when they feel stressed (29).
This study revealed that nonsmokers were more resistant to disturbing stimuli.

The craving to eat chocolate was determined to be triggered through stress or important events in North American women (30). This study found that the DI-DA scores of women who consume chocolate were significantly higher than those who did not $(\mathrm{p}=0.036)$. DI-DA scores of women with no mammography experience $(\mathrm{p}=0.020)$, and were unable to define the pain experienced during mammography $(p=0.000)$ were low (Table 3). Based on these results, women with previous mammography experience display more discomfort avoidance behaviors. Similarly, the severity of pain sensation due to the procedure increases discomfort avoidance $(\mathrm{p}<0.001)$. The DIS total score and DI sub-dimension scores of women with previous mammography experiences were higher but statistically insignificant.

The burden of having mammography was found to increase dissatisfaction (26). DA scores of women undergone mammography 
due to the presence of mass or abnormal test results were lower $(\mathrm{p}=0.041)$ than those who had control mammography in this study. Having mammography for checkup purposes resulted in more discomfort in women than the women who had a mass in the breast, and or abnormal test results. The reason for this outcome could be due to women's anxiety related to pending results.

\section{Limitations of the study}

The limitations of the study are that the study data were collected in one center and a specific time frame. The study data were written by discussing with other studies on mammography since there is no scientific study using the discomfort scale in this subject.

In conclusion, most of the women experience pain during mammography. The ability to tolerate discomfort shows how well people can tolerate conditions that disrupt comfort. Women who were not on pain relievers and non-smokers have high discomfort tolerance. Women who were consuming substances containing methylxanthine (eg. chocolate) tend to avoid discomfort. Women with a history of breast mass and abnormal test results did not avoid discomfort as much as women who undergo regular checkup mammograms.

Conducting different studies using the same scale can be useful in evaluating the discomfort experienced during mammography and its contribution to reducing pain.

Acknowledgements: We would like to thank all the patients who volunteered to contribute to this study.

Ethics Committee Approval: Approval was obtained from the Bursa Uludağ University Ethics Committee (approval number: 2016-19/6; December $\left.16^{\text {th }}, 2016\right)$ and institutional approval was obtained from the Bursa Uludag University Medical Hospital where the study was conducted.

Informed Consent: The patients were informed that participation is voluntary, and they can leave the study whenever they want, then their verbal and written approvals were obtained.

Peer-review: Externally peer-reviewed.

\section{Authorship Contributions}

Conception: N.A., M.G., Mu.G.; Design: N.A., M.G., Mu.G.; Supervision: N.A., M.G., Mu.G.; Fundings: M.G.; Materials: N.A., M.G., Mu.G.; Data Collection and/or Processing: M.G., Mu.G.; Analysis and/or Interpretation: N.A.; Literature Review: M.G., Mu.G.; Writing: N.A., M.G.; Critical Review: N.A., M.G.

Conflict of Interest: The authors declare no conflict of interest.

Financial Disclosure: No financial support was received from any company to complete this study.

\section{References}

1. Kabataş Yıldız M, Ekinci M. The relation between anger expression styles and caretaking burden of family members of cancer patients and affecting factors. Hemşirelikte Eğitim ve Araştırma Derg 2017; 14: 176-184. [Crossref]

2. Gemalmaz A, Avşar G. Cancer diagnosis and after experiences: A qualitative study. Hemşirelikte Eğitim ve Araştırma Derg 2015; 12: 93 98. [Crossref]

3. American Cancer Society, Cancer Statistics Center available at: https:// cancerstatisticscenter.cancer.org/\#!/
4. Fuller MS, Lee CI, Elmore JG. Breast cancer screening: An EvidenceBased Update Med Clin North Am 2015; 99: 451-468. (PMID: 25841594) [Crossref]

5. Freitas-Junior R, Martins E, Metran-Nascente C, Assis Carvalho A, da Silva MF, Soares LR, et al. Double-blind placebo-controlled randomized clinical trial on the use of paracetamol for performing mammography. Medicine (Baltimore) 2018; 97: e0261. (PMID: 29595685) [Crossref]

6. Narod SA, Giannakeas V, Miller AB. RE: Pan-Canadian study of mammography screening and mortality from breast cancer. J Natl Cancer Inst 2015; 107: djv094. (PMID: 25855706) [Crossref]

7. Chan $\mathrm{HH}$, Lo $\mathrm{G}$, Cheung P. Is the pain from mammography reduced by the use of a radiolucent MammoPad? Local experience in Hong Kong. Hong Kong Med J 2016; 22: 210-215. (PMID: 27101790) [Crossref]

8. den Boer D, Dam-Vervloet LAJ, Boomsma MF, de Boer E, van Dalen JA, Poot L. Clinical validation of a pressure-standardized compression mammography System. Eur J Radiol 2018; 105: 251-254. [Crossref]

9. Mendat CC, Mislan D, Hession-Kunz L. Patient comfort from the technologist perspective: factors to consider in mammographic imaging. Int J Womens Health 2017; 9: 359-364. (PMID: 28572739) [Crossref]

10. Ndikum-Moffor FM, Braiuca S, Daley CM, Gajewski BJ, Engelman KK. Assessment of mammography experiences and satisfaction among American Indian/Alaska Native Women. Womens Health Issues 2013; 23: e395-402. (PMID: 24183414) [Crossref]

11. Whelehan P, Evans A, Wells M, MacGillivray S. The effect of mammography pain on repeat participation in breast cancer screening: a systematic review. Breast 2013; 22: 389-394. [Crossref]

12. Katarzyna F, Jens-Holger G. Is individualizing breast compression during mammography useful? Investigations of pain indications during mammography relating to compression force and surface area of the compressed breast is Individualizing breast. Rofo 2017; 189: 39-48. [Crossref]

13. Paap E, Witje M, Van Landsveld-Verhoeven C, Pijnappel RM, Maas AHEM, Broeders MJM. Mammography in females with an implantedmedical device: impact on image quality, pain, and anxiety. $\mathrm{Br}$ J Radiol 2016; 89: 20160142. (PMID: 27452263) [Crossref]

14. Miller D, Livingstone V, Herbison GP. Interventions for relieving the pain and discomfort of screening mammography. Cochrane Database Syst Rev 2008; CD002942. (PMID: 18254010) [Crossref]

15. Lambertz CK, Johnson CJ, Montgomery PG, Maxwell JR, Fry SJ. Toxicity of topical lidocaine applied to the breasts to reduce discomfort during screening mammography. Journal Anaesthesiol Clin Pharmacol 2012; 28: 200-204. [Crossref]

16. Tabar L, Lebovic GS, Hermann GD, Kaufman CS, Alexander C, Sayre $\mathrm{J}$. Clinical assessment of a radiolucent cushion for mammography. Acta Radiol 2004; 45: 154-158. (PMID: 15191098) [Crossref]

17. Markle L, Roux S, Sayre JW. Reduction of discomfort during mammography utilizing a radiolucent cushioning pad. Breast J 2004; 10 : 345-349. (PMID: 15239794) [Crossref]

18. Feder K, Grunert JH. Is Individualizing Breast Compression during Mammography useful? - Investigations of pain indications during mammography relating to compression force and surface area of the compressed breast. Rofo 2017; 189: 39-48. (PMID: 28002858) [Crossref]

19. de Groot, JE, Hopman IGM, van Lier MGJTB, Branderhorst W, Grimbergen CA, den Heeten GJ. Towards personalized compression in mammography: a comparison study between pressure and forcestandardization. Eur J Radiol 2015; 84: 384-391. (PMID: 25554008) [Crossref]

20. Broeders MJM, ten Voorde M, Veldkamp WJH, van Engen RE, van Landsveld - Verhoeven C, Gunneman MNL, et al. Comparison of a flexible versus a rigid breast compression paddle: pain experience, 
projected breast area, radiation dose, and technical image quality. Eur Radiol 2015; 25: 821-829. [Crossref]

21. de Groot JE, Hopman IGM, van Lier MGJTB, Branderhorst W, Grimbergen CA, den Heeten GJ. Pressure-standardized mammography does not affect visibility, contrast, and sharpness of stable lesions. Eur J Radiol 2017; 86: 289-295. (PMID: 28027762) [Crossref]

22. Özdel K, Yalçınkaya Alkar Ö, Taymur İ, Türkçapar MH, Zamkı E, Sargın AE. "Rahatsızlığa Dayanma Ölçeği: Geçerlilik ve Güvenilirlik Çalışması". Bilişsel Davranışçı Psikoterapi ve Araştırmalar Derg 2012; 1: 52-58. [Crossref]

23. Schmidt NB, Richey JA, Fitzpatrick KK. Discomfort Intolerance: Development of a construct and measure relevant to panic disorder. J Anxiety Disord 2006; 20: 263-280. (PMID: 16564432) [Crossref]

24. Alimoğlu E, Alimoğlu MK, Kabaalioğlu A, Çeken K, Apaydın A, Lüleci E. Mamografi çekimine bağlı ağrı ve kaygı. Tanısal Girişimsel Radyoloji 2004; 10: 213-217. [Crossref]

25. Yılmaz M, Kiymaz Ö. Anxiety, and pain associated with process mammography: influence of process, information before. J Breast Health 2010; 6: 262-268. [Crossref]
26. Gabel P, Larsen MB, Nielsen PB, Svendstrup DB, Berit Andersen B. Satisfaction, discomfort, obligations, and concerns in population-based breast cancer screening: a cross-sectional study in a Danish population. BMC Health Serv Res 2017; 17: 489. [Crossref]

27. Moshina N, Sagstad S, Sebuødegård GG, Waade E, Gran J, Music S, et al. Breast compression and reported pain during mammographic screening. Radiography 2020; 26: 133-139. [Crossref]

28. Sütçigil L, Yurdakul AN, Türkçapar H. Üniversite öğrencilerinde ertelemeciliğin rahatsızlığa dayanıksızlıkla ilişkisinin incelenmesi. Boylam Psikiyatri Enstitüsü, JCBPR 2017; 6: 123-132. [Crossref]

29. Orcullo DJC, San Teo H. Understanding cognitive dissonance in smoking behavior: A qualitative study. Int J Soc Sci Humanity Stud 2016; 6: 481484. [Crossref]

30. Hormes JM, Rozin P. Premenstrual chocolate craving. What happens after menopause? Appetite 2009; 53: 256-259. (PMID: 19595725) [Crossref] 